\title{
Atypical Presentation of Methicillin-Susceptible Staphylococcus aureus Infection in a Dengue-Positive Patient: A Case Report with Virulence Genes Analysis
}

\author{
Soo Tein Ngoi ${ }^{1, *(D)}$, Yee Wan Lee ${ }^{2}$, Wen Kiong Niek ${ }^{1}$, Foong Kee Kan ${ }^{3}$, Sazaly AbuBakar ${ }^{1,4}$, \\ Sasheela Sri La Sri Ponnampalavanar ${ }^{2}$, Nuryana Idris ${ }^{1}$ and Cindy Shuan Ju Teh ${ }^{1, *}$ \\ 1 Department of Medical Microbiology, Faculty of Medicine, University of Malaya, \\ 50603 Kuala Lumpur, Malaysia; wenkiong308@gmail.com (W.K.N.); sazaly@um.edu.my (S.A.); \\ nuryana@ummc.edu.my (N.I.) \\ 2 Department of Medicine, Faculty of Medicine, University of Malaya, 50603 Kuala Lumpur, Malaysia; \\ ywlee@ummc.edu.my (Y.W.L.); sheela@ummc.edu.my (S.S.L.S.P.) \\ 3 Infectious Disease Physician, Gleneagles Hospital Medini Johor, 79250 Iskandar Puteri Johor, Malaysia; \\ kanfoongkee@gmail.com \\ 4 Tropical Infectious Diseases Research \& Education Centre (TIDREC), University of Malaya, \\ 50603 Kuala Lumpur, Malaysia \\ * Correspondence: ngoisootein@um.edu.my(S.T.N.); cindysjteh@um.edu.my (C.S.J.T.); \\ Tel.: +603-79676674 (C.S.J.T.)
}

Received: 27 January 2020; Accepted: 28 February 2020; Published: 5 March 2020

\begin{abstract}
Concurrent bacteraemia in patients with dengue fever is rarely reported. We report a case of a patient who initially presented with symptoms typical of dengue fever but later succumbed to septic shock caused by hypervirulent methicillin-susceptible Staphylococcus aureus (MSSA). A 50-year-old female patient with hypertension and diabetes mellitus presented with typical symptoms of dengue fever. Upon investigation, the patient reported having prolonged fever for four days prior to hospitalization. Within 24 hours post-admission, the patient developed pneumonia and refractory shock, and ultimately succumbed to multiple-organs failure. Microbiological examination of the blood culture retrieved a pan susceptible MSSA strain. Genomic sequence analyses of the MSSA strain identified genes encoding staphylococcal superantigens (enterotoxin staphylococcal enterotoxin $\mathrm{C} 3$ (SEC3) and enterotoxin-like staphylococcal enterotoxins-like toxin L (SEIL)) that have been associated with toxic shock syndrome in human hosts. Genes encoding important toxins (Panton-Valentine leukocidins, alpha-haemolysin, protein A) involved in the development of staphylococcal pneumonia were also present in the MSSA genome. Staphylococcus aureus co-infections in dengue are uncommon but could be exceptionally fatal if caused by a toxin-producing strain. Clinicians should be aware of the risks and signs of sepsis in dengue fever, thus allowing early diagnosis and starting of antibiotic treatment in time to lower the mortality and morbidity rates.
\end{abstract}

Keywords: bacteremia; dengue; infectious disease; MSSA; Staphylococcus aureus

\section{Introduction}

Staphylococcus aureus (S. aureus) infection manifests in a wide range of clinical symptoms, including but not limited to bacteraemia, infective endocarditis, infections of the skin, soft tissue, bones, and joints; pneumonia, device-related infections, meningitis, toxic shock syndrome, and urinary tract infections [1]. One of the most frequently encountered infections caused by S. aureus is bacteraemia, which is often associated with significant mortality once manifested in patients [2]. Multiple factors influence S. aureus bacteraemia mortality, including host factors, pathogen-host interactions, and 
pathogen-specific factors [3]. S. aureus is known for its ability to secrete multiple toxins for enhanced pathogenicity in human hosts, which often results in more severe clinical outcomes, such as toxic shock syndrome and sepsis death [4]. Staphylococcal enterotoxins (SEs) are the most prominent exotoxins produced by S. aureus during infections in humans. The superantigenic SEs over-stimulate T-lymphocytes and subsequently induce a cytokines storm in the host's immune response, which eventually leads to severe hypotension associated with toxic shock syndrome [4].

Dengue fever is one of the vector-borne diseases of great concern to public health in Malaysia. The Ministry of Health (MOH) Malaysia has documented high incidence rates of dengue fever since 2013, averaging more than 300 cases per 100,000 population on a yearly basis [5]. The endemicity of dengue virus infections in this region is attributable to the tropical climate and suboptimal environmental cleanliness due to dense populations [6,7]. While in itself is a potentially life-threatening disease, dengue patients are often predisposed to co-infections by bacteria, fungi, protozoa, and other viruses, due to dengue-associated immunosuppression [8-11]. Concurrent bacterial infections in dengue patients are rare but the number of cases is increasingly being reported within the past decade [11]. Most often, dengue with multiple infections has resulted in more severe disease manifestations and increased patient mortality $[8,12]$. It is suggested that more than half of the critically-ill dengue patients admitted to the intensive care units had concomitant bacterial infections [12].

Bacteria in the Enterobacteriaceae family, such as Escherichia coli and Salmonella spp., have been identified and remain the major causative agents recovered from dengue infections [13,14]. However, reports of staphylococcal co-infections in dengue patients have been increasingly documented in recent years, albeit at very low frequencies [14-18]. Both the methicillin-resistant and susceptible strains of S. aureus have been identified with the latter being the predominant phenotype $[14,18,19]$. Although methicillin-susceptible $S$. aureus (MSSA) appears to be more common than the methicillin-resistant $S$. aureus (MRSA), the specific cause of its predominance remains unclear. We report herein a fatal case of a community-acquired staphylococcal co-infection in a dengue patient, caused by a strain of MSSA designated as hypervirulent due to the presence of multiple virulence determinants in the genome of the bacterium.

\section{Case Presentation}

\subsection{Case History}

A 50-year-old lady, Madam N, was admitted to a hospital in the Segamat district of Johor, Malaysia with acute fever for four days with no diurnal variation or precipitating factors. It was associated with headache, nausea, myalgia, arthralgia, lethargy and reduced oral intake. She had diabetes mellitus and hypertension, but she was not compliant with her treatment and follow up. Her glycaemic control was poor with glycated haemoglobin (HbA1c) of $10.4 \%$. Upon presentation to the emergency department on 15 February 2017, her condition was stable with a blood pressure of 135/75 $\mathrm{mmHg}$ and a heart rate of 90 beats per minute. She was febrile at $38.7^{\circ} \mathrm{C}$. Clinically, she had good pulse volume, warm peripheries, and examination of the cardiovascular, respiratory and abdominal system was unremarkable. Further history revealed that she worked as a canteen operator. There was no history of any recent travels, but she stayed in a dengue-endemic area in Malaysia, where dengue fever is a major public health concern.

Her initial blood tests showed haemoglobin of $10.4 \mathrm{~g} / \mathrm{dL}$, white blood cell count $6.4 \times 10^{9} / \mathrm{L}$, platelet $102 \times 10^{9} / \mathrm{L}$ and haematocrit of $31.1 \%$. Her renal function and liver function test did not show any significant abnormality at that time (Table 1). A presumptive diagnosis of dengue fever day 4 of illness was made. A dengue serology rapid test was done which showed dengue NS1 positive, while dengue IgM and IgG were negative by Rapid test. 
Table 1. Blood investigation results ${ }^{1}$.

\begin{tabular}{|c|c|c|c|c|c|c|c|}
\hline Date & $15 / 2$ & $15 / 2$ & $15 / 2$ & $16 / 2$ & $16 / 2$ & $16 / 2$ & $16 / 2$ \\
\hline $\mathrm{Hb}(\mathrm{g} / \mathrm{dL})$ & 10.4 & 14.0 & 13.1 & 14.1 & 14.4 & 14.1 & 15.4 \\
\hline $\mathrm{WBC}\left(\times 10^{9} / \mathrm{L}\right)$ & 6.4 & 8.1 & 7.9 & 2.2 & 2.7 & 1.3 & 2.2 \\
\hline HCT L/L (\%) & 31.1 & 40.8 & 39 & 42.7 & 44.2 & 42.3 & 46.9 \\
\hline Platelet $\left(\times 10^{9} / \mathrm{L}\right)$ & 102 & 126 & 109 & 95 & 121 & 90 & 68 \\
\hline Lactate $(\mathrm{mmol} / \mathrm{L})$ & & & & 6.0 & 4.8 & 7.2 & 9.8 \\
\hline Urea $(\mathrm{mmol} / \mathrm{L})$ & 4.3 & & & 3.4 & 5.2 & & \\
\hline Sodium (mmol/L) & 125 & & & 127 & 128 & & \\
\hline Potassium (mmol/L) & 3.4 & & & 3.1 & 3.2 & & \\
\hline Creatinine $(\mu \mathrm{mol} / \mathrm{L})$ & 71 & & & 62 & 101 & & \\
\hline Bilirubin $(\mu \mathrm{mol} / \mathrm{L})$ & 9.1 & & & 11.4 & 13.7 & & \\
\hline Albumin $(\mathrm{g} / \mathrm{L})$ & 38.3 & & & 30.9 & 24.9 & & \\
\hline $\operatorname{ALP}(\mathrm{U} / \mathrm{L})$ & 84 & & & 68 & 60 & & \\
\hline ALT (U/L) & 47.3 & & & 41.4 & 44.2 & & \\
\hline AST (U/L) & 84.5 & & & 165.9 & & & \\
\hline $\mathrm{CK}(\mathrm{U} / \mathrm{L})$ & 157 & & & 2735 & & & \\
\hline LDH (U/L) & 247 & & & 406 & & & \\
\hline CRP (mg/L) & & & & 301.21 & & & \\
\hline $\operatorname{ESR}(\mathrm{mm} / \mathrm{h})$ & & & & 15 & & & \\
\hline \multicolumn{8}{|l|}{$\mathrm{ABG}$} \\
\hline pH & & & & 7.218 & 7.228 & & 7.217 \\
\hline $\mathrm{pCO}_{2}(\mathrm{mmHg})$ & & & & 49.2 & 42.5 & & 28.8 \\
\hline $\mathrm{pO}_{2}(\mathrm{mmHg})$ & & & & 46.8 & 105 & & 101 \\
\hline $\mathrm{HCO}_{3}(\mathrm{mmol} / \mathrm{L})$ & & & & 17.2 & 16.7 & & 13.2 \\
\hline
\end{tabular}

${ }^{1} \mathrm{Hb}$ : Haemoglobin; WBC: White blood cell; HCT: Haematocrit; ALP: Alkaline phosphatase; ALT: Alanine transaminase; AST: Aspartate transaminase; CK: Creatine kinase; LDH: Lactate dehydrogenase; CRP: C-reactive protein; ESR: Erythrocyte sedimentation rate; $\mathrm{ABG}$ : Arterial blood gas; $\mathrm{pCO}_{2}$ : Partial pressure of carbon dioxide; $\mathrm{pO}_{2}$ : Partial pressure of oxygen; $\mathrm{HCO}_{3}$ : Bicarbonate.

As the initial assessment was stable, she was admitted to the general medical ward. She was started on intravenous normal saline hydration of $2 \mathrm{cc} / \mathrm{kg} / \mathrm{hr}$. Upon review in the morning, about 8 hours after admission, she was noted to be breathless. Her peripheries were cold, and saturation was only $92 \%$ under high flow oxygen of $15 \mathrm{~L} / \mathrm{min}$. Her blood pressure was 180/90 $\mathrm{mmHg}$, and she was tachycardic at 148 beats/min. Auscultation of the lungs revealed bilateral crepitations. Arterial blood gas showed severe lactic acidosis with type 1 respiratory failure. She was immediately transferred to the intensive care unit (ICU) and was intubated. She was given a dose of ceftriaxone $2 \mathrm{~g}$ to treat for pneumonia. The total fluid balance overnight was positive $1505 \mathrm{cc}$.

Over the next 12 hours, her condition deteriorated rapidly despite adequate fluid resuscitation. Fluid given was adjusted accordingly to central venous pressure monitoring. She was also given a whole blood transfusion and supported with maximum inotropic support. Antibiotics were changed to meropenem as her condition further deteriorated and doxycycline was added for atypical infections coverage. There was no evidence of any occult bleeding to suggest dengue haemorrhagic fever. She remained persistently lactic acidosis. Unfortunately, the district hospital did not have continuous renal replacement therapy service and she was not stable to be transferred to a tertiary centre. A bedside transthoracic echocardiogram showed a good heart function with an ejection fraction of $65 \%$, no regional wall motion abnormalities and no obvious vegetation. An electrocardiogram showed sinus tachycardia with no ischaemic changes to suggest a cardiac event.

She developed multi-organ dysfunction and refractory shock, and she succumbed to her condition in less than 24 hours from admission. Subsequently, her blood culture grew MSSA and her C-reactive protein was elevated. Her hepatitis B, hepatitis $C$ and human immunodeficiency virus (HIV) screening was negative. There was no obvious wound or abscess seen on clinical examination. In view of her rapid deterioration and subsequent death due to severe sepsis with concomitant dengue fever, we sent her blood culture sample for further genomic analysis to further study the strain's virulence and pathogenicity factors. 


\subsection{Identification of Virulence Determinants in MSSA Genome}

The MSSA strain was sent to a research laboratory at the University of Malaya for genomic assessment and was coded as HS-MSSA. The genomic DNA of the HS-MSSA strain was extracted using a commercial DNA extraction kit (Qiagen, Hilden, Germany) and subjected to whole-genome sequencing via the Illumina Miseq platform (GA2x, pipeline version 1.80) by a commercial sequencing vendor. This Whole Genome Shotgun project has been deposited at the National Center for Biology Information (NCBI) GenBank under the accession number VCMW00000000. The version described in this paper is version VCMW01000000. Virulence determinants in the draft genome of HS-MSSA were identified by using the web-based tool VFanalyzer which retrieves virulence gene sequences from the curated database of Virulence Factors for Pathogenic Bacteria (VFDB; http://www.mgc.ac.cn/VFs/) [17]. Virulence factors related to bacterial adherence, enzyme production, host immune evasion, secretion system and toxins production were identified in the genome of the HS-MSSA strain (Table 2). Multiple toxin genes encoding for exfoliative toxin (type A), haemolysins (alpha, beta, gamma, and delta), staphylococcal enterotoxin C (subtype SEC3) and SE-like toxin L (SEIL), exotoxins, leukotoxins, and Panton-Valentine leukocidins (PVL) were identified in the genome of HS-MSSA strain. The global accessory gene regulator operon (agr $\mathrm{ABCD}$ ) and the staphylococcal accessory regulator (sar) system were also identified in the HS-MSSA genome.

Table 2. Virulence genes identified in HS-MSSA genome ${ }^{1}$.

\begin{tabular}{|c|c|c|c|}
\hline Virulence Factor & Gene & Contig & Sequence Region (bp) \\
\hline \multicolumn{4}{|l|}{ Adherence } \\
\hline$\overline{\text { Autolysin }}$ & atl & 2 & $172,186-175,965$ \\
\hline Cell wall-associated fibronectin-binding protein & $e b h$ & 15 & $17,112-29,540$ \\
\hline Collagen adhesion & cna & 19 & $142,053-142,376$ \\
\hline Elastin binding protein & $e b p$ & 15 & $78,470-79,936$ \\
\hline $\begin{array}{l}\text { Extracellular adherence protein/MHC analogous } \\
\text { protein }\end{array}$ & eap/map & 11 & $50,777-52,522$ \\
\hline Fibrinogen binding proteins & efb & 12 & $69,305-69,802$ \\
\hline Fibronectin binding proteins & fnbA & 6 & $7942-11,022$ \\
\hline Fibronectin binding proteins & $f n b B$ & 6 & $4386-7193$ \\
\hline Intercellular adhesin & $i c a A$ & 19 & $115,805-117,004$ \\
\hline Intercellular adhesin & $i c a B$ & 19 & $117,249-118,142$ \\
\hline Intercellular adhesin & $i c a C$ & 19 & $118,129-119,181$ \\
\hline Intercellular adhesin & $i c a R$ & 19 & $115,042-115,602$ \\
\hline Staphylococcal protein A & spa & 10 & $91,167-92,729$ \\
\hline \multicolumn{4}{|l|}{ Enzyme } \\
\hline$\overline{\text { Cysteine protease }}$ & $\operatorname{ssp} B$ & 2 & $166,228-167,361$ \\
\hline Cysteine protease & $\operatorname{sspC}$ & 2 & $165,861-166,190$ \\
\hline Hyaluronate lyase & hys $A$ & 21 & $38,536-40,908$ \\
\hline Lipase & geh & 32 & $23,616-25,688$ \\
\hline Lipase & lip & 19 & $119,572-121,617$ \\
\hline Serine V8 protease & $\operatorname{ssp} A$ & 2 & $167,491-168,519$ \\
\hline Serine protease & spla & 4 & $383,603-384,310$ \\
\hline \multirow{2}{*}{ Serine protease } & \multirow{2}{*}{ splB } & 4 & $381,976-382,698$ \\
\hline & & 4 & $382,756-383,478$ \\
\hline Serine protease & splC & 4 & $381,199-381,918$ \\
\hline \multirow{2}{*}{ Serine protease } & \multirow{2}{*}{ splD } & 4 & $378,589-379,308$ \\
\hline & & 4 & $380,362-381,078$ \\
\hline \multirow{2}{*}{ Serine protease } & \multirow{2}{*}{ splE } & 4 & $377,715-378,431$ \\
\hline & & 4 & $379476-380192$ \\
\hline Serine protease & splF & 4 & $376,845-377,564$ \\
\hline Staphylocoagulase & coa & 18 & $71,941-73,923$ \\
\hline \multirow{2}{*}{ Thermonuclease } & \multirow{2}{*}{ nuc } & 2 & $5253-5807$ \\
\hline & & 27 & $92,177-92,749$ \\
\hline Zinc metalloproteinase aureolysin & aur & 19 & $67,567-69,096$ \\
\hline \multicolumn{4}{|l|}{ Immune evasion } \\
\hline 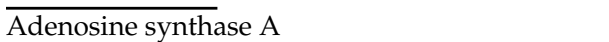 & $\operatorname{ads} A$ & 10 & $54,213-56,555$ \\
\hline
\end{tabular}


Table 2. Cont.

\begin{tabular}{|c|c|c|c|}
\hline Virulence Factor & Gene & Contig & Sequence Region (bp) \\
\hline \multirow{15}{*}{ Capsule } & \multirow{15}{*}{-} & 36 & $12,417-13,085$ \\
\hline & & 36 & $13,101-13,787$ \\
\hline & & 36 & $13,790-14,554$ \\
\hline & & 36 & $14,763-16,397$ \\
\hline & & 36 & $16,387-17,415$ \\
\hline & & 36 & $17,422-18,537$ \\
\hline & & 36 & $18,541-19,665$ \\
\hline & & 36 & $19,668-20,747$ \\
\hline & & 36 & $20,740-22,134$ \\
\hline & & 36 & $22,131-22,688$ \\
\hline & & 36 & $22,697-23,935$ \\
\hline & & 36 & $25,185-25,742$ \\
\hline & & 36 & $25,742-26,629$ \\
\hline & & 36 & $26,683-27,945$ \\
\hline & & 36 & $28,034-29,167$ \\
\hline Staphylococcal complement inhibitor & $s c n$ & 11 & $54,281-54,631$ \\
\hline Staphylococcal binder of immunoglobulin & $s b i$ & 5 & $117,022-118,335$ \\
\hline Secretion system & & & \\
\hline$\overline{\text { Type VII secretion system }}$ & esaA & 35 & $15,975-19,004$ \\
\hline \multirow{5}{*}{ Type VII secretion system } & $e s a B$ & 35 & $19,434-19,676$ \\
\hline & & 35 & $30,637-31,077$ \\
\hline & & 35 & $31,088-31,588$ \\
\hline & & 35 & $31,599-32,099$ \\
\hline & & 35 & $32,110-32,610$ \\
\hline \multirow{6}{*}{ Type VII secretion system } & $\rho \in \rho G$ & 35 & $32,621-33,112$ \\
\hline & esaG & 35 & $33,739-34,239$ \\
\hline & & 35 & $34,250-34,741$ \\
\hline & & 32 & 2354-2854 \\
\hline & & 32 & $2865-3365$ \\
\hline & & 32 & $3376-3864$ \\
\hline Type VII secretion system & ess $A$ & 35 & $19,004-19,462$ \\
\hline Type VII secretion system & $e s s B$ & 35 & $19,689-21,023$ \\
\hline Type VII secretion system & $e s s C$ & 35 & $21,084-25,493$ \\
\hline Type VII secretion system & $e s x A$ & 35 & $15,599-15,892$ \\
\hline \multicolumn{4}{|l|}{ Toxin } \\
\hline$\overline{\text { Alpha hemolysin }}$ & hly/hla & 12 & $72,363-73,331$ \\
\hline Beta hemolysin & hlb & 11 & $53,721-53,921$ \\
\hline Delta hemolysin & hld & 38 & $2974-3108$ \\
\hline Enterotoxin C & $\mathrm{sec}$ & 13 & $58,618-59,418$ \\
\hline Enterotoxin-like L & sell & 13 & $59,585-60,307$ \\
\hline Exfoliative toxin type A & eta & 3 & $7742-8689$ \\
\hline Exotoxin & $\operatorname{set} 15$ & 14 & $2106-2801$ \\
\hline Exotoxin & $\operatorname{set} 16$ & 13 & $65,639-66,319$ \\
\hline Exotoxin & $\operatorname{set} 18$ & 13 & $67,591-68,661$ \\
\hline Exotoxin & set 21 & 13 & $71,399-72,094$ \\
\hline Exotoxin & $\operatorname{set} 22$ & 13 & $72,516-73,211$ \\
\hline Exotoxin & set 24 & 13 & $74,632-75,330$ \\
\hline Exotoxin & set 25 & 13 & $75,617-76,378$ \\
\hline Exotoxin & set 33 & 13 & $69,011-69,901$ \\
\hline Exotoxin & set 34 & 13 & $70,250-70,969$ \\
\hline Exotoxin & set 37 & 13 & $73,548-74,252$ \\
\hline Exotoxin & set7 & 13 & $66,545-67,300$ \\
\hline Gamma hemolysin & $h \lg A$ & 5 & $118,835-119,800$ \\
\hline Gamma hemolysin & $\operatorname{hlg} B$ & 5 & $121,316-122,293$ \\
\hline Gamma hemolysin & hlgC & 5 & $120,367-121,314$ \\
\hline Leukocidin subunit $\mathrm{G}$ & $l u k G$ & 11 & $10,300-11,316$ \\
\hline Leukocidin subunit $\mathrm{H}$ & $l u k H$ & 11 & $9223-10,278$ \\
\hline Leukotoxin D & lukD & 4 & $388,427-389,410$ \\
\hline Leukotoxin E & $l u k E$ & 4 & $389,412-390,346$ \\
\hline Panton-Valentine leukocidin & $l u k F-P V$ & 4 & $259-1236$ \\
\hline Panton-Valentine leukocidin & $l u k S-P V$ & 4 & $1238-2185$ \\
\hline
\end{tabular}

${ }^{1}$ Details of the predicted virulence genes in the HS-MSSA genome are provided in the Supplementary Table S1. 


\subsection{Antimicrobial Susceptibility Testing}

The Kirby-Bauer disk diffusion method was used to determine the antimicrobial susceptibility profile of the HS-MSSA strain according to the Clinical and Laboratory Standards Institute (CLSI) guideline (2018) [20]. The HS-MSSA strain was found to be pan-susceptible to all antimicrobial agents tested. The growth of the HS-MSSA strain was effectively inhibited by amoxicillin-clavulanate, cefoxitin, ceftriaxone, ciprofloxacin, clindamycin, cloxacillin, erythromycin, fusidic acid, gentamicin, penicillin-G, piperacillin-tazobactam, rifampicin, and sulfamethoxazole-trimethoprim.

\section{Discussion}

This is the first case report of recovery and identification of a hypervirulent MSSA co-infection in a dengue patient in Malaysia. The bacterial infection was classified as community-acquired due to its rapid onset within 24 hours post-admission. The patient initially presented as dengue fever and not in shock at the time of admission. However, the patient rapidly developed symptoms of pneumonia and refractory shock and succumbed to multiorgan failures despite intensive therapeutic efforts. Isolation of an MSSA strain from the patient's blood culture confirmed bacteraemia in the patient. Genomic sequence analyses revealed multiple virulence determinants within the genome of HS-MSSA.

Upon admission, the patient was presumptively diagnosed as dengue fever based on clinical presentations, and subsequent serology, tests showed positive dengue NS1 protein. NS1-based dengue tests are often specific (specificity ranged between $86.1 \%$ and $100 \%$ ), but the sensitivity varies greatly depending on the dengue virus serotypes, duration of illness, and types of infection (primary or secondary dengue) [21]. Although uncommon, a false-positive result could occur in dengue NS1 testing due to cross-reactions with other flaviviruses, such as zika virus [22,23]. False-positive dengue NS1 tests have also been documented in patients with haematological malignancies [24]. Simultaneous testing of NS1 with IgM and IgG antibodies is essential for enhanced accuracy in dengue diagnosis $[25,26]$. However, dengue-specific IgM and IgG antibodies tested negative in the patient's serum during the serology testing. Nonetheless, the patient was at day 4 of illness during the time of admission, and very often, the detection of dengue-specific antibodies is only possible after 4 or 5 days of disease onset, with acceptable diagnostic accuracy on the sixth day onwards $[27,28]$. Unfortunately, the patient had succumbed to multiple organ failure within 24 hours post-admission. Hence, further testing could not be done to confirm dengue virus infection.

S. aureus often harbours multiple toxin genes in its genome, and the most prominent toxins are the staphylococcal superantigens (staphylococcal enterotoxins, SEs; SE-like proteins, SEls; toxic shock syndrome toxin 1, TSST-1) [4]. The presence of genes encoding for SEC3 and SEIL in the HS-MSSA genome infers its ability to produce these potent immunostimulatory superantigenic toxins. These superantigens are capable of binding directly to the major histocompatibility complex class II molecules on the antigen-presenting cells (APC) outside of the antigen groove, thus bypassing APC processing prior to $\mathrm{T}$ cell presentation [4]. This subsequently leads to the activation of an abundance of $\mathrm{T}$ cells, causing the massive release of chemokines and pro-inflammatory cytokines that eventually result in lethal toxic shock syndrome. The SEC, together with SEB, is the predominant SE serotype of S. aureus that causes non-menstrual toxic shock syndrome. Besides superantigenic activity, SEs and SEls are also pyrogenic, emetic (only for SEs), and capable of inducing lethal hypersensitivity to endotoxins [29].

Staphylococcal pneumonia is often associated with the production of PVL, protein A, and alpha-haemolysin by S. aureus [30]. The presence of these genes in the genome of HS-MSSA could have explained the manifestation of pneumonia in the patient. A previous study by Labandeira-Rey et al. [31] showed that PVL alone is sufficient to cause pneumonia. Moreover, the expression of PVL could further induce changes in the transcriptional levels of the genes encoding both secreted and cell-associated virulence factors in S. aureus [31]. Alpha-haemolysin is capable of causing damage to lung epithelial tissue, and when combined with high levels of PVL, often results in severe necrotizing pneumonia in humans [32]. Protein A, at the same time, induces an inflammatory response of the airway by activating 
the tumour-necrosis factor- $\alpha$ receptor, TNFR1, hence playing an essential role in the pathogenesis of staphylococcal pneumonia [33].

PVL-producing S. aureus has been found to cause life-threatening infection and does not respond to antimicrobial treatment despite in vitro susceptibility to the antimicrobial agents, resulting in a clinical condition termed PVL syndrome [34]. PVL syndrome is commonly caused by community-acquired S. aureus infection, with a higher frequency of methicillin-susceptible subtypes [34]. A similar observation was made in this clinical case, whereby the patient's condition did not improve after the administration of ceftriaxone, meropenem, and doxycycline, despite in vitro susceptibility of the HS-MSSA strain to these antimicrobial agents later being verified by laboratory tests. In a previously reported PVL-producing S. aureus infection, the patient was eventually treated with a combination of clindamycin and daptomycin [34]. This notion supported the empirical use of clindamycin in patients to prevent possible toxin-mediated sepsis.

Virulence genes expression in S. aureus is mainly regulated by the agr system (agr ABCD and delta-haemolysin) $[35,36]$. Together with the staphylococcal accessory regulator (sar) system, the agr system is found to upregulate the expression of SEB and SEC [4]. Besides that, the role of the agr system is also proved to be essential in the pathogenesis of acute lethal staphylococcal pneumonia by regulating the expression of alpha-haemolysin [37]. The pathogenicity of the HS-MSSA strain might be attributed to the concerted efforts of the intact agr and sar systems in regulating the expression of the array of virulence genes in its genome. Moreover, the hypervirulence of the HS-MSSA strain could explain the predominance of MSSA over MRSA in concurrent bacteraemia in dengue patients. Nonetheless, future studies involving more $S$. aureus isolates from dengue dual infections should be conducted to verify this hypothesis.

The majority of the prominent toxin-producing genes are found in regions with considerable genetic variations, mostly associated with phage regions within the HS-MSSA genome (Unpublished data). Contig-13, which harbours multiple enterotoxins and exotoxins, was predicted as an incomplete phage region associated with the superantigen-encoding staphylococcal pathogenicity island (SaPI). Contig-4 harbours multiple virulence factors including leukotoxins (PVL and LukED) within a phage region that also encodes for SaPIn3-associated proteins. The leukotoxin LukGH identified in contig-11 was found located next to a phage region. All these evidences support the previous notion that highly mobile genetic elements, such as phage-associated pathogenicity islands, play an important role in the evolution of this hypervirulent $S$. aureus lineage by providing survival advantages to enhance its pathogenicity and host-adaptability [38].

Most often, the outcome of a disease does not depend solely on the pathogenicity of the etiologic agent, but host factors play an equally important role. The vulnerability in the host immune defence mechanisms and microbial virulence involves a two-way host-pathogen interaction, causing severe sepsis in the host [39]. In the fatal sepsis reported in this case, the patient's immune system might have been suppressed by the dengue virus, resulting in host vulnerability to MSSA co-infection. Evidence has shown that in neonates and the elderly, immune cells infected by dengue virus produced fewer cytokines leading to an immunosuppressed state of the hosts [40]. Indeed, dengue patients with concurrent bacteraemia are often older and tended to have prolonged fever [41]. In Malaysia, $90 \%$ of fatal cases of dengue haemorrhagic fever occurred in adult females with a median age of 32-years and an average of 4.7 days of illness prior to hospitalization [42]. Old age is the most prominent risk factor associated with dengue mortality in Malaysia [43]. Moreover, underlying comorbidities, particularly hypertension and diabetes mellitus, are commonly associated with more severe dengue cases and greater mortality rates [8,12,42]. The combined effect of old age (50-year-old), prolonged duration of fever (4 days), comorbid chronic illnesses (hypertension and diabetes mellitus), and concurrent bacteraemia by an enterotoxin-producing strain of MSSA, might have caused the rapid deterioration and eventually the death of the dengue patient in this case.

To date, there are still limited effective emergency therapeutic options for established refractory shock. Short-term mortality occurs in $50 \%$ of critically ill patients who developed refractory shock [44]. 
Therefore, early and aggressive interventions should be implemented before refractory shock develops. Nandhabalan and colleagues who are experienced in toxin-mediated sepsis have recommended the use of adjunctive antimicrobial therapy, where clindamycin is administered empirically in addition to broad-spectrum antibiotics until microbiological analyses have proven the absence of toxin-producing pathogens, or until organs' dysfunction are stabilised [45]. Clindamycin functions to inhibit bacterial protein synthesis and most importantly, prevents the production of superantigens and is clinically proven to be effective in the treatment of toxic shock syndrome [46]. Nonetheless, increasing clindamycin resistance has been observed among $S$. aureus populations during recent years [47]. Therefore, more regional susceptibility data should be collected, and clinicians should be aware of antimicrobial resistance patterns of the MSSA population when choosing empirical regimens.

This case report documents the first virulence analysis of an MSSA strain isolated in a fatal case of dengue dual infections in Malaysia. The presence of multiple virulence factors, especially the superantigens SEC3 and SEIL, together with the regulatory genes, might have contributed to the hypervirulence of the HS-MSSA strain. Although concurrent bacteraemia in dengue patients remains rarely reported, especially one caused by $S$. aureus, the greater mortality risk of such dual infections should not be overlooked. Early diagnosis and interventions are essential to prevent unfavourable clinical outcomes in patients. Upon examination of patients presenting symptoms of dengue fever, the attending physicians should also consider the possibility of false-positive serology test results and bacteraemia. Delayed diagnosis can prove fatal especially when patients are infected by toxin-producing bacterial pathogens, where bacteraemia can rapidly develop into refractory septic shock and death may occur within a short time. Further, the lack of reporting and attention for concurrent bacteraemia in dengue patients in Malaysia necessitates increasing efforts in surveillance. The actual prevalence of co-infections and the characteristics of the etiologic agents may help medical practitioners in making appropriate medical decisions and treatment regimens to prevent dengue mortality.

Supplementary Materials: The following are available online at http://www.mdpi.com/2076-0817/9/3/190/s1, Table S1: Details of the virulence genes identified in the HS-MSSA genome and the reference genomes (showing the specific gene accession numbers) used.

Author Contributions: Conceptualization, C.S.J.T. and F.K.K.; Resources, Y.W.L. and F.K.K.; Methodology, C.S.J.T.; Investigation, S.T.N. and W.K.N.; Formal analysis, S.T.N., Y.W.L., S.A., S.S.L.S.P. and N.I.; Visualization, S.T.N. and Y.W.L.; Writing-Original Draft, S.T.N. and Y.W.L.; Supervision, C.S.J.T. All authors have read and agreed to the published version of the manuscript.

Funding: This research was partially funded by University of Malaya Research Fund Assistance (BKP), grant number BK075-2016.

Acknowledgments: We thank the diagnostic laboratory staff in the hospital in the Segamat district of Johor for the technical support in retrieving and transportation of the HS-MSSA isolate.

Conflicts of Interest: The authors declare no conflict of interest.

\section{References}

1. Tong, S.Y.C.; Davis, J.S.; Eichenberger, E.; Holland, T.L.; Fowler, V.G. Staphylococcus aureus infections: Epidemiology, pathophysiology, clinical manifestations, and management. Clin. Microbiol. Rev. 2015, 28, 603-661. [CrossRef]

2. Thomer, L.; Schneewind, O.; Missiakas, D. Pathogenesis of Staphylococcus aureus bloodstream infections. Annu. Rev. Pathol. 2016, 11, 343-364. [CrossRef]

3. Van Hal, S.J.; Jensen, S.O.; Vaska, V.L.; Espedido, B.A.; Paterson, D.L.; Gosbell, I.B. Predictors of mortality in Staphylococcus aureus bacteremia. Clin. Microbiol. Rev. 2012, 25, 362-386. [CrossRef]

4. Liu, D. Enterotoxin-producing Staphylococcus aureus. In Molecular Medical Microbiology, 2nd ed.; Tang, Y.W., Sussman, M., Liu, D., Poxton, I., Schwartzman, J., Eds.; Academic Press: Boston, MA, USA, 2015; pp. $979-995$.

5. Ministry of Health (MOH) Malaysia Virtual Library: Health Facts. Available online: http://vlib.moh.gov. my/cms/content.jsp?id=com.tms.cms.section.Section_2e813304-a0188549-d5315d00-719f1e10 (accessed on 16 May 2019). 
6. Hii, Y.L.; Zaki, R.A.; Aghamohammadi, N.; Rocklöv, J. Research on climate and dengue in Malaysia: A systematic review. Curr. Environ. Health Rep. 2016, 3, 81-90. [CrossRef] [PubMed]

7. Mohd-Zaki, A.H.; Brett, J.; Ismail, E.; L'Azou, M. Epidemiology of dengue disease in Malaysia (2000-2012): A systematic literature review. PLOS Negl. Trop. Dis. 2014, 8, e3159. [CrossRef] [PubMed]

8. Lahiri, M.; Fisher, D.; Tambyah, P.A. Dengue mortality: Reassessing the risks in transition countries. Trans. R. Soc. Trop. Med. Hyg. 2008, 102, 1011-1016. [CrossRef] [PubMed]

9. Salam, N.; Mustafa, S.; Hafiz, A.; Chaudhary, A.A.; Deeba, F.; Parveen, S. Global prevalence and distribution of coinfection of malaria, dengue and chikungunya: A systematic review. BMC Public Health 2018, 18, 710. [CrossRef]

10. Suzuki, S.; Kitazawa, T.; Ota, Y.; Okugawa, S.; Tsukada, K.; Nukui, Y.; Matsubara, T. Dengue hemorrhagic shock and disseminated candidiasis. Intern. Med. 2007, 46, 1043-1046. [CrossRef]

11. Trunfio, M.; Savoldi, A.; Vigano, O.; d'Arminio Monforte, A. Bacterial coinfections in dengue virus disease: What we know and what is still obscure about an emerging concern. Infection 2017, 45, 1-10. [CrossRef]

12. Chen, C.M.; Chan, K.S.; Yu, W.L.; Cheng, K.C.; Chao, H.C.; Yeh, C.Y.; Lai, C.C. The outcomes of patients with severe dengue admitted to intensive care units. Medicine 2016, 95, e4376. [CrossRef]

13. Pancharoen, C. Coinfections in dengue patients. Pediatric Infect. Dis. J. 1998, 17, 81-82. [CrossRef] [PubMed]

14. Syue, L.S.; Tang, H.J.; Hung, Y.P.; Chen, P.L.; Li, C.W.; Li, M.C.; Ko, W.C. Bloodstream infections in hospitalized adults with dengue fever: Clinical characteristics and recommended empirical therapy. J. Microbiol. Immunol. Infect. 2019, 52, 225-232. [CrossRef] [PubMed]

15. Miyata, N.; Yoshimura, Y.; Tachikawa, N.; Amano, Y.; Sakamoto, Y.; Kosuge, Y. Cavity forming pneumonia due to Staphylococcus aureus following dengue fever. Am. J. Trop. Med. Hyg. 2015, 93, 1055-1057. [CrossRef] [PubMed]

16. Nagassar, R.P.; Bridgelal-Nagassar, R.J.; McMorris, N.; Judith Roye-Green, K. Staphylococcus aureus pneumonia and dengue virus co-infection and review of implications of coinfection. BMJ Case Rep. 2012, 2012, bcr0220125804. [CrossRef] [PubMed]

17. Sunderalingam, V.; Kanapathipillai, T.; Edirisinghe, P.A.S.; Dassanayake, K.M.M.P.; Premawansa, I.H.G.S. Dengue viral myositis complicated with rhabdomyolysis and superinfection of methicillin-resistant Staphylococcus aureus. Case Rep. Infect. Dis. 2013, 2013, 1-3.

18. Thein, T.L.; Ng, E.L.; Yeang, M.S.; Leo, Y.S.; Lye, D.C. Risk factors for concurrent bacteremia in adult patients with dengue. J. Microbiol. Immunol. Infect. 2017, 50, 314-320. [CrossRef]

19. Chai, L.Y.A.; Lim, P.L.; Lee, C.C.; Hsu, L.Y.; Teoh, Y.L.; Lye, D.C.B.; Leo, Y.S. Cluster of Staphylococcus aureus and dengue co-infection in Singapore. Ann. Acad. Med. Singap. 2007, 36, 847-850.

20. Clinical and Laboratory Standards Institute (CLSI). CLSI supplement M100. In Performance Standards for Antimicrobial Susceptibility Testing, 28th ed.; CLSI: Wayne, PA, USA, 2018.

21. Osorio, L.; Ramirez, M.; Bonelo, A.; Villar, L.A.; Para, B. Comparison of the diagnostic accuracy of commercial NS1-based diagnostic tests for early dengue infection. Virol. J. 2010, 7, 1-10. [CrossRef]

22. Gyurech, D.; Schilling, J.; Schmidt-Chanasit, J.; Cassinotti, P.; Kaeppeli, F.; Dobec, M. False positive dengue NS1 antigen test in a traveller with an acute Zika virus infection imported into Switzerland. Swiss Med. Wkly. 2016, 146, 1-3. [CrossRef]

23. Fernanda Estofolete, C.; Terzian, A.C.; Bernardes Parreira, R.; Esteves, A.; Hardman, L.; Greque, G.V.; Nogueira, M.L. Clinical and laboratory profile of Zika virus infection in dengue suspected patients: A case series. J. Clin. Virol. 2016, 81, 25-30. [CrossRef]

24. Chung, S.J.; Krishnan, P.U.; Leo, Y.S. Two cases of false-positive dengue non-structural protein 1 (NS1) antigen in patients with hematological malignancies and a review of the literature on the use of NS1 for the detection of dengue infection. Am. J. Trop. Med. Hyg. 2015, 92, 367-369. [CrossRef] [PubMed]

25. Blacksell, S.D.; Jarman, R.G.; Bailey, M.S.; Tanganuchitcharnchai, A.; Jenjaroen, K.; Gibbons, R.V.; Day, N.P. Evaluation of six commercial point-of-care tests for diagnosis of acute dengue infections: The need for combining NS1 antigen and IgM/IgG antibody detection to achieve acceptable levels of accuracy. Clin. Vaccine Immunol. 2011, 18, 2095-2101. [CrossRef] [PubMed]

26. Wang, S.M.; Sekaran, S.D. Early diagnosis of dengue infection using a commercial dengue duo rapid test kit for the detection of NS1, IgM, and IgG. Am. J. Trop. Med. Hyg. 2010, 83, 690-695. [CrossRef] [PubMed]

27. Hu, D.; Di, B.; Ding, X.; Wang, Y.; Chen, Y.; Pan, Y.; Che, X. Kinetics of non-structural protein 1, IgM and IgG antibodies in dengue type 1 primary infection. Virol. J. 2011, 8, 1-4. [CrossRef] 
28. Ruechusatsawat, K.; Morita, K.; Tanaka, M.; Vongcheree, S.; Rojanasuphot, S.; Warachit, P.; Igarashi, A. Daily observation of antibody levels among dengue patients detected by enzyme-linked immunosorbent assay (ELISA). Jpn. J. Trop. Med. Hyg. 1994, 22, 9-12. [CrossRef]

29. Hu, D.L.; Wang, L.; Fang, R.; Okamura, M.; Ono, H.K. Staphylococcus aureus enterotoxins. In Staphylococcus aureus; Fetsch, A., Ed.; Academic Press: Cambridge, MA, USA, 2018; pp. 39-55.

30. Taylor, T.A.; Unakal, C.G. Staphylococcus aureus; StatPearls Publishing: Las Vegas, NV, USA, 2018.

31. Labandeira-Rey, M.; Couzon, F.; Boisset, S.; Brown, E.L.; Bes, M.; Benito, Y.; Vandenesch, F. Staphylococcus aureus panton-valentine leukocidin causes necrotizing pneumonia. Science 2007, 315, 1130-1133. [CrossRef]

32. Mairpady Shambat, S.; Chen, P.; Nguyen Hoang, A.T.; Bergsten, H.; Vandenesch, F.; Siemens, N.; Svensson, M. Modelling staphylococcal pneumonia in a human 3D lung tissue model system delineates toxin-mediated pathology. Dis. Models Mech. 2015, 8, 1413-1425. [CrossRef]

33. Gómez, M.I.; Lee, A.; Reddy, B.; Muir, A.; Soong, G.; Pitt, A.; Prince, A. Staphylococcus aureus protein A induces airway epithelial inflammatory responses by activating TNFR1. Nat. Med. 2004, 10, 842-848. [CrossRef]

34. Schefold, J.C.; Esposito, F.; Storm, C.; Heuck, D.; Krüger, A.; Jörres, A.; Hasper, D. Therapy-refractory Panton-Valentine Leukocidin-positive community-acquired methicillin-sensitive Staphylococcus aureus sepsis with progressive metastatic soft tissue infection: A case report. J. Med. Case Rep. 2007, 1, 1-6. [CrossRef]

35. Arvidson, S.; Tegmark, K. Regulation of virulence determinants in Staphylococcus aureus. Int. J. Med. Microbiol. 2001, 291, 159-170. [CrossRef]

36. Dinges, M.M.; Orwin, P.M.; Schlievert, P.M. Exotoxins of Staphylococcus aureus. Clin. Microbiol. Rev. 2000, 13, 16-34. [CrossRef] [PubMed]

37. Wardenburg, J.B.; Patel, R.J.; Schneewind, O. Surface proteins and exotoxins are required for the pathogenesis of Staphylococcus aureus pneumonia. Infect. Immun. 2007, 75, 1040-1044. [CrossRef] [PubMed]

38. Novick, R.P.; Ram, G. Staphylococcal pathogenicity islands-movers and shakers in the genomic firmament. Curr. Opin. Microbiol. 2017, 38, 197-204. [CrossRef] [PubMed]

39. Van der Poll, T.; Opal, S.M. Host-pathogen interactions in sepsis. Lancet Infect. Dis. 2008, 8, 32-43. [CrossRef]

40. Valero, N.; Mosquera, J.; Levy, A.; Añez, G.; Marcucci, R.; Alvarez-Mon, M. Differential induction of cytokines by human neonatal, adult, and elderly monocyte/macrophages infected with dengue virus. Viral Immunol. 2014, 27, 151-159. [CrossRef]

41. Lee, I.K.; Liu, J.W.; Yang, K.D. Clinical characteristics and risk factors for concurrent bacteremia in adults with dengue hemorrhagic fever. Am. J. Trop. Med. Hyg. 2005, 72, 221-226. [CrossRef]

42. Sam, S.S.; Omar, S.F.S.; Teoh, B.T.; Abdul-Jamil, J.; AbuBakar, S. Review of dengue hemorrhagic fever fatal cases seen among adults: A retrospective study. PLOS Negl. Trop. Dis. 2013, 7, e2194. [CrossRef]

43. Liew, S.M.; Khoo, E.M.; Ho, B.K.; Lee, Y.K.; Omar, M.; Ayadurai, V.; Chinna, K. Dengue in Malaysia: Factors associated with dengue mortality from a national registry. PLoS ONE 2016, 11, e0157631. [CrossRef]

44. Jentzer, J.C.; Vallabhajosyula, S.; Khana, A.K.; Chawla, L.S.; Busse, L.W.; Kashani, K.B. Management of refractory vasodilatory shock. CHEST 2018, 154, 416-426. [CrossRef]

45. Nandhabalan, P.; Ioannou, N.; Meadows, C.; Wyncoll, D. Refractory septic shock: Our pragmatic approach. Crit. Care 2018, 22, 215. [CrossRef]

46. Carapetis, J.R.; Jacoby, P.; Carville, K.; Ang, S.J.J.; Curtis, N.; Andrews, R. Effectiveness of clindamycin and intravenous immunoglobulin, and risk of disease in contacts, in invasive group A streptococcal infections. Clin. Infect. Dis. 2014, 59, 358-365. [CrossRef] [PubMed]

47. Acree, M.E.; Morgan, E.; David, M.Z. S. aureus infections in Chicago, 2006-2014: Increase in CA MSSA and decrease in MRSA incidence. Infect. Cont. Hosp. Epidemiol. 2017, 38, 1226-1234. [CrossRef] [PubMed]

(C) 2020 by the authors. Licensee MDPI, Basel, Switzerland. This article is an open access article distributed under the terms and conditions of the Creative Commons Attribution (CC BY) license (http://creativecommons.org/licenses/by/4.0/). 